\title{
Corrosion Behaviour of Electroless Deposited Ni-P/BN(h) Composite Coating
}

\author{
Chih-I Hsu ${ }^{1}$, Gao-Liang Wang ${ }^{2, *}$, Ming-Der Ger ${ }^{3}, K_{\text {Kung-Hsu Hou }}^{4, *}$ \\ ${ }^{1}$ School of Defense Science, Chung Cheng Institute of Technology, National Defense University, \\ Taoyuan, Taiwan \\ ${ }^{2}$ Department of Marketing Management, Takming University of Science and Technology, Taipei, \\ Taiwan \\ ${ }^{3}$ Department of Chemistry and Material Engineering, Chung Cheng Institute of Technology, National \\ Defense University, Taoyuan, Taiwan \\ ${ }^{4}$ Department of Power Vehicle and Systems Engineering, Chung Cheng Institute of Technology, \\ National Defense University, Taoyuan, Taiwan \\ *E-mail: khou@ndu.edu.tw, khoucloud@gmail.com, wanggl@ takming.edu.tw
}

doi: 10.20964/2016.06.19

Received: 14 February 2016 / Accepted: 29 March 2016 / Published: 4 May 2016

\begin{abstract}
In this study, self-lubrication $\mathrm{BN}(\mathrm{h})$ particles successfully co-deposited on Ni-P coating through electroless deposition process, and conduct research for the Ni-P/BN(h) composite coating surface morphology, microstructure, mechanical properties and corrosion behaviour. Scanning electron microscopy (SEM) and atomic force microscope (AFM) were used to observe the micro morphology of coating, and X-ray diffraction (XRD) to analyse crystalline phase. The corrosion resistance was evaluated through polarization curves and electrochemical impedance spectroscopy (EIS) in 3.5 wt.\% $\mathrm{NaCl}$ solution at room temperature. The results show that the hardness of Ni-P/BN(h) composite coating can be improved after heat treatment. According to the results of corrosion testing in the 3.5 wt.\% $\mathrm{NaCl}$ solution, the corrosion resistance of electroless $\mathrm{Ni}-\mathrm{P} / \mathrm{BN}(\mathrm{h})$ composite coatings has been strengthened due to barrier effect by $\mathrm{BN}(\mathrm{h})$ particles, compared to a conventional $\mathrm{Ni}-\mathrm{P}$ coating.
\end{abstract}

Keywords: Electroless, Ni-P/BN(h) Composite coating, Mechanical properties, Corrosion resistance

\section{FULL TEXT}

(C) 2016 The Authors. Published by ESG (www.electrochemsci.org). This article is an open access article distributed under the terms and conditions of the Creative Commons Attribution license (http://creativecommons.org/licenses/by/4.0/). 